\title{
PENGABDIAN KEPADA MASYARAKAT DENGAN ASUHAN KEBIDANAN PADA PASIEN RETENSIO PLACENTADI PUSKESMAS PEMBANTU GOLODUKAL, KECAMATAN LANGKE REMBONG, KABUPATEN MANGGARAI
}

DOI: https://doi.org/10.33024/jkpm.v4i5.4126

\section{Dionesia Octaviani Laput ${ }^{1 *}$, Eufrasia Prinata Padeng ${ }^{2}$, Putriatri Krimasusini Senudin ${ }^{3}$, Fransiska Nova Nanur ${ }^{4}$, Aveliana Savanera Baptis ${ }^{5}$ \\ 1-5Prodi DIII Kebidanan, Universitas Khatolik Santu Paulus Ruteng}

Disubmit: 25 Maret 2021 Diterima: 06 Mei $2021 \quad$ Diterbitkan: 30 September 2021

Email Korespondensi: dinnylaput9@gmail.com

\begin{abstract}
ABSTRAK
Setiap wanita akan melalui proses kehamilan, persalinan, nifas hal tersebut merupakan proses yang fisiologis. Selama menjalani proses tersebut kemungkinan terjadi masalah kesehatan yang dapat menimbulkan kesakitan bahkan kematian baik pada ibu dan bayi. Tujuan kegiatan ini untuk mempelajari dan memahami asuhan kebidanan pada ibu hamil, bersalin, nifas, neonates dan KB secara komprehensif. Metode yang digunakan adalah metode penelitian kualitatif deskriptif dengan pendekatan studi kasus tujuh langkah varney. Tehnik pengambilan data melalui wawancara, observasi langsung dan studi dokumen rekam medic. Analisa data dilakukan secara deskriptif berdasarkan tujuh langkah varney. Hasil kegiatan ini adalah Ny. M.G.L umur 26 tahun, G2P1A0, ibu bersalin dengan retensio placenta dan penatalaksanaan manual placenta sesuai standar SOP di tingkat pelayanan primer, nifas normal, BBL normal dan ibu menggunakan KB suntik 3 bulanan.
\end{abstract}

Kata kunci : Asuhan kehamilan, bersalin, Retensio Placenta.

\section{ABSTRACT}

Every woman will go through a process of pregnancy, childbirth, childbirth, this is a physiological process. During this process, there may be health problems that can cause pain and even death to both mother and baby. The purpose of this activity is to learn and understand midwifery care for pregnant women, childbirth, postpartum, neonates and family planning in a comprehensive manner. The method used is descriptive qualitative research method with a seven-step varney case study approach. Data collection techniques through interviews, direct observation and study of medic record documents. The data analysis was done descriptively based on the seven varney steps. The result of this activity is Mrs. M.G.L, 26 years old, G2P1AO, a mother giving birth with retained placenta and manual management of the placenta according to SOP standards at the primary care level, normal postpartum, normal LBW and the mother uses 3-monthly injection contraceptives.

Key words: Pregnancy care, childbirth, Retensio Placenta. 


\section{PENDAHULUAN}

Asuhan kebidanan berkesinambungan adalah pelayanan yang diberikan mulai dari kehamilan sampai kepada pelayanan keluarga berencana sehingga dapat mencegah komplikasi yang dapat mengancam jiwa ibu sedini mungkin serta diharapkan dapat menurunkan AKI dan AKB. Asuhan kebidanan yang diberikan yaitu secara efektif, aman dan holistik terhadap ibu hamil, bersalin, nifas dan menyusui, bayi baru lahir dan kesehatan reproduksi pada kondisi normal. Pelayanan ini tentunya dilaksanakan berdasarkan standar praktik kebidanan dan kode etik profesi. (PUSDIKNAKES, 2014)

Menurut laporan World Health Organization (WHO) mengenai status kesehatan Nasional pada pencapaian target Sustainable Development Goals (SDGs) menyatakan secara global sekitar 830 wanita meninggal setiap hari karena komplikasi selama kehamilan dan persalinan dengan AKI sebanyak 216 / 100.000 kelahiran hidup dan sebanyak $99 \%$ kematian ibu akibat masalah kehamilan, persalinan atau kelahiran terjadi di negara - negara berkembang. Rasio AKI masih dirasa cukup tinggi sebagaimana di targetkan menjadi 70 / 100.000 kelahiran hidup pada tahun 2030 (WHO, 2018). AKI di Indonesia pada tahun 2015 sebesar 305 / 100.000 kelahiran hidup, namun tidak mencapai target MDGs yaitu 102 / 100.000 kelahiran hidup. Target penurunan AKI tahun 2020 menjadi 205 / 100.000 kelahiran hidup dan pada tahun 2030 menjadi 131 / 100.000 kelahiran hidup dengan rata - rata penurunan sebesar 5,5\% per tahun dan AKB sebanyak 22 / 1000 kelahiran hidup (Kemenkes RI 2019)

Pada tahun 2015 AKI di Propinsi NTT sebesar 133 / 100.000 kelahiran hidup, tahun 2017 sebanyak 163 kasus, tahun 2018 sebanyak 142 kasus tahun 2019 sebanyak 98 kasus dan AKB tahun 2017 sebanyak 1104 kasus, tahun 2018 sebanyak 912 kasus, tahun 2019 sebanyak 822 kasus). (Dinkes NTT 2018)

Berdasarkan data, Kabupaten Manggarai selama periode 3 tahun jumlah kasus AKI per 100.000 kelahiran hidup mengalami fluktuatif. Kasus kematian pada tahun 2016 sebanyak 7 kasus $(113,23 / 100.000)$ kelahiran hidup dan mengalami penurunan pada tahun 2017 menjadi 5 kasus $(81,93 / 100.000)$ kelahiran hidup. Namun pada tahun 2018 kasus kematian ibu mengalami peningkatan sebanyak 6 kasus $(98,36 / 100.000)$ kelahiran hidup dan AKB tahun 2017 sebanyak 70 kasus, tahun 2018 meningkat sebanyak 83 kasus, dan tahun 2019 menurun sebanyak 76 kasus (Profil Kesehatan Kabupaten Manggarai). Untuk Puskesmas La'o tahun 2017, tahun 2018 dan tahun 2019 AKI tidak ada sedangkan AKB 9 kasus dengan rincian BBLR 5, asfiksia 3, cacat bawaan 1 dan untuk Pustu Golodukal tahun 2019 AKI tidak ada sedangkan AKB 2 dengan rician lahir mati 1 (imaturus 27 minggu) dan asfiksia 1. (Dinas Kesehatan Kabupaten Manggarai 2017)

Kehamilan adalah masa yang di mulai dari konsepsi yang di hitung dari hari pertama haid terakhir (HPHT) sampai lahirnya janin dan merupakan hal yang fisiologis. Kehamilan mempunyai kemungkinan terbesar terjadi pada wanita yang telah mensturasi dan mempunyai organ reproduksi yang sehat yang terjadi karena adanya hubungan seksual dengan seorang pria dengan organ reproduksi sehat pula(Padeng et al. 2021). Cakupan pelayanan kesehatan ibu hamil tahun 2018 untuk Indonesia mencakup K1 95,75 \% dan K4 87,48 \%( Kemenkes RI, 2019 ) sedangkan Propinsi NTT cakupan K1 sebesar 78,02 \% dan K4 sebesar 56,06 \% (Profil Kesehatan Propinsi NTT, 2018) dan untuk Kabupaten Manggarai tahun 2018 cakupan K1 100 \% dan K4 80,43\% (Profil Kesehatan Kabupaten Manggarai, 2018), Puskesmas La'o K1 100 \% dan K4 70,9 \% dan Pustu Golodukal K1 96,40 \% dan K4 95,23 \%(Dinas Kesehatan Kabupaten Manggarai 2017)

Persalinan adalah proses pengeluaran hasil konsepsi (janin dan placenta) yang telah cukup bulan atau yang dapat hidup di luar kandungan melalui jalan lahir 
atau melalui jalan lain dengan bantuan atau tanpa bantuan (kekuatan sendiri). Proses ini di mulai dengan adanya kontraksi persalinan sejati, yang di tandai dengan perubahan serviks secara progresif dan di akhiri dengan kelahiran placenta (Sulityawati, 2010). Berdasarkan data tahun 2018 terdapat 90,32 \% persalinan yang di tolong oleh tenaga kesehatan sementara persalinan di tolong tenaga kesehatan di fasilitas pelayanan kesehatan sebesar 90,32\% (Kemenkes,2019) dan

untuk Propinsi NTT persalinan tenkes sebesar $90 \% \quad$ (Profil kesehatan Propinsi NTT) kabupaten Manggarai persalinan sebesar 98,06 \% (Profil Kesehatan Kabupaten Manggarai, 2018), Puskesmas La'o sebesar 99,6\% dan pustu Golodukal sebesar 99,5\%(Dinas Kesehatan Kabupaten Manggarai 2017)

Masa nifas (Puerperium) adalah di mulai setelah placenta lahir dan berakhir ketika alat - alat kandungan kembali seperti keadaan sebelum hamil. Masa nifas berlangsung selama kira - kira 6 minggu. Wanita yang memulai puerperium disebut puerpura. Puerperium (nifas) berlangsung selama 6 minggu atau 42 hari, merupakan waktu yang di perlukan untuk pulihnya kandungan pada keadaan yang normal (Soleha, 2009). Cakupan kunjungan nifas di Indonesia KF lengkap menunjukan kecenderungan meningkat menjadi 85,92 \% dan Propinsi NTT cakupan KF lengkap sebesar 58,27 \%(Kemenkes RI, 2019 ), sementara Kabupaten Manggarai KF1 97,8 \%, KF lengkap 89,6\% (Profil Kesehatan Kabupaten Manggarai, 2018) dan Puskesmas La'o KF1 96,3 \%, KF lengkap 95,3 \% dan Pustu Golodukal KF1 sebesar 94,15 \%, KF lengkap 96,25 \% (Dinas Kesehatan Kabupaten Manggarai 2017)

Bayi baru lahir normal adalah bayi yang lahir dalam presentase belakang kepala melalui vagina tanpa memakai alat pada usia kehamilan 37 - 40 minggu dengan berat badan 2500 - 4000 gram, nilai apgar > 7 dan tanpa cacat bawaan (Dewi, 2010). Cakupan KN 1 di Indonesia tahun 2018 sebesar 97,36 \% lebih tinggi dari tahun 2017 yaitu sebesar 92,62 \% , KN lengkap 91,39 \% dan untuk Propinsi NTT cakupan KN 1 63,36 \% sedangkan untuk KN lengkap cakupan terendah untuk semua Propinsi di Indonesia sebesar 60,17 \% (Kemenkes RI, 2019) dan Kabupaten Manggarai KN1 98,30 \%, KN lengkap 93 \% (Profil Kesehatan Kabupaten Manggarai, 2018) dan untuk Puskesmas La'o KN1 98,6 \%, KN lengkap 92,8 \% sedangkan Pustu Golodukal KN1 93,20 \% dan KN lengkap 95,40 \%.(Dinas Kesehatan Kabupaten Manggarai 2017)

Keluarga berencana (Family Planning, Planned Parenthood) adalah suatu usaha untuk menjarangkan atau merencanakan jumlah dan jarak kehamilan dengan memakai kontrasepsi (Anggraini dan Martini, 2011). Cakupan peserta KB aktif tahun 2018 sebesar 63,27 \%, peserta KB baru 47,78 \%, jumlah PUS 14,87 \% (Profil kesehatan Indonesia, 2018), untuk NTT cakupan KB aktif 69 \% (Profil kesehatan Propinsi NTT, 2018) sedangkan Kabupaten Manggarai jumlah PUS 65.222 orang, jumlah PUS peserta KB aktif 34.147 orang $(52,4 \%$ ) (Profil Kesehatan Kabupaten Manggarai, 2018) dan untuk Puskesmas La'o jumlah PUS 5.720 orang dengan rincian kondom 35 (1\%), IUD 1.031 (20,3\%), Suntik 1.279 (35,1\%), pil 616 (17,2\%) dan Pustu Golodukal peserta KB aktif 808 (85,75\%)(Dinas Kesehatan Kabupaten Manggarai 2017)

Kehamilan dengan faktor resiko adalah di mana kondisi ibu hamil yang dapat menyebabkan kemungkinan resiko atau bahaya terjadinya komplikasi pada persalinan yang dapat menyebabkan kematian atau kesakitan pada ibu dan bayinya. Salah satunya adalah terjadinya retensio placenta dalam persalinan. Retensio placenta adalah terlambatnya kelahiran placenta selama setengah jam setelah persalinan bayi. Retensio placenta dapat menyebabkan perdarahan yang merupakan penyebab kematian nomor satu (40\% - $60 \%$ ) kematian ibu melahirkan 
di Indonesia dan merupakan salah satu penyebab perdarahan post partum yang dapat mengancam jiwa ibu di mana perdarahan yang hebat akan cepat dan tidak mendapat perawatan medis yang akan mempercepat kematian (Sulistyawati, 2011). Berdasarkan data profil kesehatan kabupaten Manggarai tahun 2018 Penyebab Kematian Ibu dari 6 kasus kematian tersebut adalah sebagai berikut : Perdarahan: 4 kasus (Perdarahan karena Retensio Plasenta: 3 Kasus dan Perdarahan Karena Atonia Uteri : 1 kasus).

Dari hasil penapisan pada ibu hamil di Pustu Golodukal yang di lakukan pada tanggal 12 Maret 2020 pada Ny. M.G.L G2P1A0, umur 26 tahun, usia kehamilan 30 minggu 6 hari, di lakukan skrining menggunakan kartu skor puji rohayati dengan nilai 2 sehingga ibu termasuk pada kategori kehamilan dengan resiko ringan dan pada persalinan kala 1, kala 2 normal sedangkan kala 3 disertai penyulit yaitu Retensio Placenta. Karena pada kala III dapat pula terjadi gangguan atau kelainan patologis dalam bentuk perdarahan post partum, retensio placenta inversion uteri dan perdarahan robekan jalan lahir.

Upaya pemerintah untuk mewujudkan tujuan pembangunan kesehatan Ibu dan Anak adalah menurunkan AKI dan AKB baik secara nasional maupun secara regional kabupaten manggarai. Atas dasar ini penulis tertarik untuk mengambil judul Laporan Tugas Akhir "Asuhan Kebidanan komprehensif pada Ny. M.G.L umur 26 tahun G2P1A0 dengan Retensio Placenta di puskesmas Pembantu Golodukal.

\section{MASALAH}

Dari hasil penapisan pada ibu hamil di Pustu Golodukal yang di lakukan pada tanggal 12 Maret 2020 pada Ny. M.G.L G2P1A0, umur 26 tahun, usia kehamilan 30 minggu 6 hari, di lakukan skrining menggunakan kartu skor puji rohayati dengan nilai 2 sehingga ibu termasuk pada kategori kehamilan dengan resiko ringan dan pada persalinan kala 1, kala 2 normal sedangkan kala 3 disertai penyulit yaitu Retensio Placenta. Karena pada kala III dapat pula terjadi gangguan atau kelainan patologis dalam bentuk perdarahan post partum, retensio placenta inversion uteri dan perdarahan robekan jalan lahir.

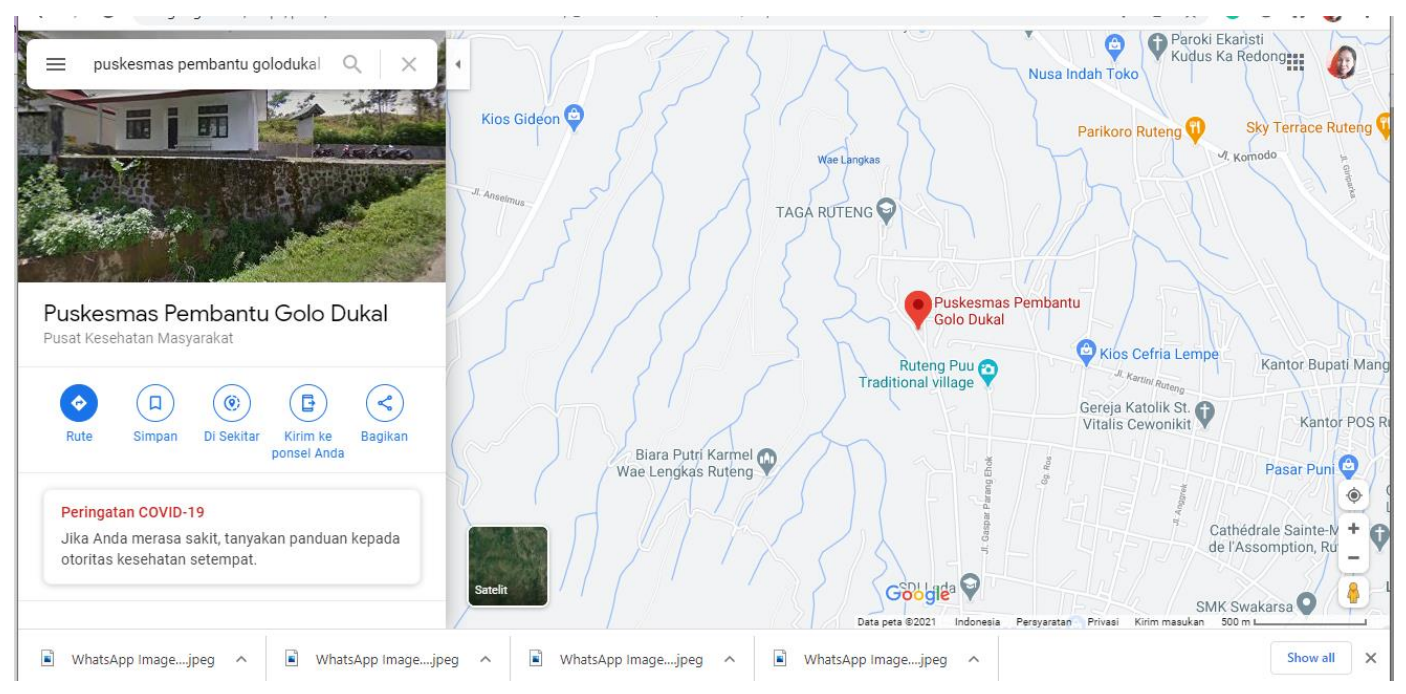

Gambar 2.1 Peta Lokasi Kegitan Pengabdian Kepada Masyarakat 


\section{METODE}

a. observasi.

Observasi dilakukan pada setiap kunjungan dalam bentuk pemeriksaan kepada ibu melalui inspeksi, palpasi, auskultasi maupun perkusi serta pada kunjungan pertama kehamilan di dukung dengan adanya pemeriksaan penunjang yaitu pemeriksaan laboratorium seperti pemeriksaan kadar $\mathrm{HB}$, malaria, hepatitis, syphilis, HIV. Observasi ini di lakukan selama \pm 2 bulan atau sampai ibu mengikuti salah satu metode KB

b. Wawancara

Pada studi kasus ini wawancara di lakukan langsung kepada ibu pada saat kunjungan pertama kehamilan sebagai pengkajian data awal meliputi biodata, keluhan ibu, riwayat haid, riwayat perkawinan, riwayat obstetric laud an sekarang, riwayat $\mathrm{KB}$, riwayat kesehatan ibu, pola kebiasaan sehari - hari. Wawancara kepada suami meliputi biodata, riwayat kesehatan keluarga, riwayat social dan budaya dan Wawancara kepada petugas kesehatan dalam hal ini bidan mengenai kunjungan yang dilakukan ibu.

c. Dokumentasi

Pada studi kasus ini dokumen pendukung berupa data yang di peroleh dari kartu ibu, register kohort ibu, buku KIA, partograf dan catatan harian peneliti.

Adapun pelaksanaan kegiatan ini dibagi menjadi 7 tahapan yaitu :

a) Pengumpulan Data

b) Pada langkah pertama ini di lakukan pengkajian dengan mengumpulkan semua data yang di perlukan untuk mengevaluasi keadaan klien secara lengkap, yaitu : anamnesa terdiri dari data subjektif dan data objektif, riwayat kesehatan, pemeriksaan fisik pada kesehatan, meninjau catatan terbaru atau catatan sebelumnya, meninjau data laboratorium dan membandingkan dengan hasil studi.

c) Interpretasi data

d) Pada langkah ini di lakukan interpretasi data yang benar terhadap diagnose atau masalah dan kebutuhan klien berdasarkan interpretasi yang benar atas data - data yang telah di kumpulkan.

e) Data dasar yang sudah di kumpulkan di interpretasikan sehingga di temukan masalah atau diagnose yang spesifik.

f) Mengidentifikasikan diagnose atau masalah potensial.

g) Pada langkah ini kita mengidentifikasikan masalah atau diagnose potensial lain berdasarkan rangkaian masalah dan diagnose yang sudah di identifikasikan

h) Mengidentifikasikan dan menetapkan kebutuhan yang memerlukan penanganan segera.

i) Mengidentifikasikan perlunya tindakan segera oleh bidan untuk segera di konsultasikan atau di tangani bersama dengan anggota tim kesehatan yang lain sesuai kondisi klien.

j) Merencanakan asuhan yang menyeluruh

k) Pada langkah ini di rencanakan asuhan yang menyeluruh di tentukan oleh langkah - langkah sebelumnya. Semua keputusan yang di kembangkan dalam asuhan menyeluruh ini harus rasional dan benar - benar valid berdasarkan pengetahuan pengetahuan dan teori serta sesuai dengan asumsi tentang apa yang akan atau tidak akan di lakukan oleh klien

l) Melaksanakan perencanaan 
m) Pada langkah ini rencana asuhan menyeluruh seperti pada langkah kelima harus di laksanakan secara efisien dan aman. Manajemen yang efisien akan menyingkat waktu dan biaya serta meningkatkan mutu dari asuhan klien.

n) evaluasi

o) Pada langkah terakhir ini di lakukan evaluasi keefektifan dari asuhan yang sudah di berikan meliputi pemenuhan kebutuhan akan bantuan apakah benar - benar telah terpenuhi sesuai dengan sebagaimana telah di identifikasi di dalam masalah dan diagnose.

p) Rencana tersebut di anggap efektif jika memang benar efektif di dalam pelaksanaannya. Ada kemungkinan bahwa sebagian rencana tersebut telah efektif sedang sebagian belum efektif.

\section{HASIL DAN PEMBAHASAN}

a. Asuhan Kebidanan Kehamilan

Pada saat melakukan pengkajian pada kunjungan Ny.M.G.L semuanya normal. Skrining menggunakan kartu skor Puji Rohyati nilai skor 2. Menurut Skor Puji Rohyati,Ny.M.G.Ltermasuk ibu hamil dengan resiko ringan. Selama kehamilan ini Ny.M.G.L mengeluh mual muntah pada awal kehamilan sampai kehamilan usia 12 minggu, pada TM 2 ibu mengatakan tidak ada keluhan dan pada saat TM 3 ibu mengeluh sakit pinggang dan kadang - kadang nyeri pada sympisis yang merupakan ketidaknyamanan dalam semester III yang di alami oleh ibu hamil tua, yang dialami adalah keluhan yang fisiologis secara teori hal tersebut disebabkan karena kepala janin masuk kedalam rongga panggul, maka asuhan yang diberikan tentang ketidaknyamanan pada trimester III, hal yang fisiologis karena perkembangan janin semakin besar dan kepala janin masuk dalam rongga panggul,cara mengatasinya istirahat yang cukup, dan pijit pinggang yang nyeri. Selama jadwal ANC, Ny.M.G.L memperoleh asuhan kebidanan yang sesuai standar (10T) yaitu timbang berat badan dan ukur tinggi badan, ukur tekanan darah, ukur LILA, ukur Tinggi frundus uteri, tentukan presentasi janin dan DJJ, imunisasi TT, tablet FE, periksa laboratorium, tata laksanan, temu wicara. Pelayanan $10 \mathrm{~T}$ yang diperoleh Ny.M.G.L sudah sesuai dengan teori tentang standar asuhan kebidanan pada masa kehamilan (KEMENKES RI 2017)

Berdasarkan data tersebut Ny.M.G.L termasuk kedalam kategori ibu hamil resiko ringan. Asuhan kebidanan yang diberikan yaitu pendidikan kesehatan tentang tanda bahaya kehamilan TM III, ketidaknyamanan pada kehamilan TM III, menganjurkan ibu rutin mengkonsumsi tablet tambah darah, tanda-tanda persalinan.

\section{b. Asuhan Kebidanan Persalinan}

Saat ini umur kehamilan ibu 39 minggu 3 hari sehingga kehamilan ibu telah aterm bahwa kehamilan cukup bulan adalah 37-42 minggu (Sarwono Prawirhadjo 2010).

\section{1) Kala I.}

Tanggal 10 Mei 2020 pukul 02.30 wita ibu di antar oleh keluarga dan suaminya ke Puskesmas Pembantu Golodukal. Ibu mengatakan sakit perut bagian bawah menjalar ke pinggang sudah semakin sering dan teratur, keluar lendir dan darah dari jalan lahir sejak pukul 20.00 wita tanggal 10 Mei 2020 di rumah ibu. Hal tersebut menunjukan bahwa ibu mengalami tanda pasti persalinan yaitu his datang lebih kuat dan teratur diikuti keluarnya lendir bercampur darah yang menandakan 
jalan lahir mulai membuka (Wahyuni and Wahyuningsih 2015). Dilakukan pemeriksaan tanda - tanda vital dalam batas normal dan di lakukan pemeriksaan dalam pembukaan $9 \mathrm{~cm}$, bagian bawah janin sudah berada di hodge III. Diberikan asuhan sayang ibu yaitu menganjurkan ibu untuk tidur miring ke kiri, mengajarkan tehnik relaksasi, serta pemenuhan kebutuhan nutrisi pada saat tidak ada his. Pada pukul 02.55 wita ketuban pecah spontan berwarna jernih, kepala sudah membuka vulva $5-6 \mathrm{~cm}$.

2) Kala II.

Pada pukul 02.55 wita ketuban pecah spontan berwarna jernih dan kepala sudah membuka vulva 5-6 cm. Ibu mengatakan adanya dorongan yang kuat untuk mengedan dan sakitnya sudah semakin sering dan kuat. Ibu di pimpin mengedan dan pukul 03.00 wita bayi lahir spontan langsung menangis warna kulit kemerahan, gerakan aktif. Jenis kelamin laki-laki. Kala II yang di alami Ny. M.G.L berlangsung selama 5 menit, sesuai dengan teori(Varney 2008) menyebutkan pada multi gravida kala II berlangsung kurang lebih 1 jam.

3) Kala III.

Segera setelah bayi lahir dalam 1 menit pertama di lakukan penyuntikan oksitosin 10 IU di berikan secara intra muscular kemudian melakukan peregangan tali pusat terkendali jika terdapat his. Hasil evaluasi tidak ada tanda - tanda pelepasan placenta yaitu tampak tali pusat memanjang, ada semburan darah tiba-tiba. Mengecek kembali kandung kemih hasil kandung kemih kosong. Pukul 03.15 wita mengecek kembali tanda - tanda pelepasan placenta ternyata masih belum ada tanda - tanda pelepasan placenta lalu di berikan injeksi oksitosin ulangan yang ke II dosis 10 IU di berikan secara intra muscular. Pukul 03.20 wita mengecek kembali tanda - tanda pelepasan placenta dan hasilnya belum juga ada tanda - tanda pelepasan placenta. Pukul 03.30 wita kembali mengecek tanda - tanda pelepasan placenta hasilnya juga belum ada kemajuan karena tali pusat tidak bertambah panjang. Hasil kolaborasi dengan dokter SPOG, Ny. M.G.L di diagnose retensio placenta dan instruksi dokter lakukan manual placenta. Hal ini sesuai dengan teori mengatakan retensio placenta adalah tertahannya atau belum lahirnya placenta hingga atau melebihi waktu 30 menit setelah bayi lahir dan teori (Mochtar, 1998 ) mengatakan bahwa retensio placenta adalah keadaan di mana placenta belum lahir dalam waktu 1 jam setelah bayi lahir. Pukul 03.35 wita suami dan ibu di jelaskan tentang hasil pemeriksaan dan keadaan ibu juga tindakan yang akan di laksanakan yaitu manual placenta. Setelah di beri penjelasan, ibu dan suami bersedia untuk di lakukan tindakan medis manual placenta lalu di berikan inform consent untuk persetujuan tindakan medis. Sesuai protap PPGDON penatalaksanaan manual placenta sebelum melaksanakan tindakan medis dilakukan pemasangan infus 2 jalur yaitu infus RL Drips oksitosin 20 IU 20 tetes / menit di tangan kanan dan infus RL tetes cepat di tangan kiri untuk pencegahan syok hipovolemik dan pemberian antibiotika $500 \mathrm{mg} 1$ tablet di berikan secara oral untuk pencegahan infeksi setelah tindakan medis. Mengobservasi kembali keadaan umum pasien dalam keadaan baik, kesadaran composmentis, dan pemeriksaan tanda - tanda vital dalam batas normal. Pukul 03.40 wita melakukan tindakan manual placenta (sesuai dengan protap PPGDON penatalaksanaan manual placenta).

Pukul 04.00 wita placenta berhasil di lahirkan lengkap lalu lakukan eksplorasi untuk memastikan tidak ada selaput placenta yang masih melekat pada dinding uterus untuk mencegah perdarahan dan atonia uteri. Penanganan pasca manual placenta tetap di lakukan yaitu memantau kesadaran, keadaan umum, tanda - tanda vital, kontraksi uterus dan perdarahan. Observasi perdarahan \pm 200 cc dan kontraksi uterus teraba keras, TFU 2 jari di bawah pusat. 
Ada laserasi pada perineum derajat 2 dan di lakukan heacting jelujur. Berdasarkan data di atas dapat di simpulkan lama manajemen aktif kala III berlangsung 1 jam dari bayi baru lahir karena retensio placenta dan pananganannya manual placenta. Prosedur manual placenta sudah sesuai dengan SOP Protap PPGDON penatalaksanaan manual placenta dan tidak ada kesenjangan antara teori dan praktek. Hasil evaluasi placenta sudah lahir, keadaan ibu normal, tidak terjadi syok hipovolemik dan tidak ada tanda - tanda infeksi. Asuhan yang di berikan yaitu pendidikan kesehatan cara mencegah terjadinya perdarahan, infeksi luka jahitan dan menganjurkan ibu untuk makan dan minum.

\section{c. Asuhan Kebidanan Bayi Baru Lahir}

Pada pengkajian ini bayi Ny.M.G.L lahir normal usia kehamilan 39 minggu 3 hari dilakukan 3 penilaian awal yaitu bayi menangis kuat, gerak aktif, warna kulit kemerahan. Dari hasil pengkajian didapat dikatakan bayi Ny.M.G.L dalam keadaan normal (Dewi 2010). Pemeriksaan antropometri yaitu BB 3000 gram, PB $50 \mathrm{~cm}$, LK $33 \mathrm{~cm}$, LD $34 \mathrm{~cm}$, ini yang menyatakan bahwa pemeriksaan antropometri normal yaitu BB 2500-4000 gram, PB 48-52 cm, LD 30-38cm, LK 33$35 \mathrm{~cm}$ (Dewi,2010). Bayi Ny.M.G.L sudah mendapat injeksi vitamin $\mathrm{K}$ dengan dosis $0,1 \mathrm{mg}$ pada paha sebelah kiri secara IM dengan sudut $90^{\circ}$, pemberian salep mata pada kedua mata bayi, dan setelah satu jam kemuadian diberikan imunisasi Hepatitis B 0,5 ml pada paha bagian kanan secara IM dengan $90^{\circ}$. Hal ini sesuai dengan teori yang menyatakan bahwa asuhan segera setelah bayi baru lahir yaitu pemberian salep mata pada kedua mata bayi, vitamin $\mathrm{K}$ yang diberikan setelah bayi lahir dengan dosis $0,1 \mathrm{mg}$ diberikan secara IM, di paha kiri anterolateral dan pemberian imunisasi $\mathrm{Hb} 0$ bahwa batas pemberian $\mathrm{Hb} 0$ maksimal adalah 12 jam setelah bayi lahir(Rahayu 2018). Asuhan segera pada bayi baru lahir yang diberikan juga meliputi membersihkan jalan nafas, mengeringkan seluruh tubuh bayi kecuali telapak tangan, memotong tali pusat merupakan asuhan segera pada bayi baru lahir adalah asuhan yang diberikan pada bayi tersebut selama jam pertama setelah kelahiran. Perawatan yang diberikan pada bayi segera sesudah lahir baik pervaginam atau dengan SC ialah mempertahankan suhu tubuh bayi yaitu dibungkus hangat dan diselimuti, tunda memandikan 6-24 jam setelah bayi baru lahir untuk mencegah terjadinya hipotermi, membersihkan jalan nafas bila diperlukan yaitu dengan menghisap lendir dari mulut ke hidung dengan menggunakan penghisap lendir setril, dan mengeringkan tubuh bayi kecuali bagian tangan dan memberikan rangsang taktil yaitu menggosok punggung, perut, dada atau tungkai bayi dengan telapak tangan, potong dan ikat tali pusat kira-kira 2 menit setelah melahirkan. Bayi dilakukan IMD. Hal ini sesuai dengan teori Saifuddin,2010 bahwa asuhan segera bayi baru lahir adalah asuhan yang diberikan pada bayi tersebut selama jam pertama setelah kelahiran. Perawatan yang diberikan pada bayi segera sesudah lahir baik pervaginam atau SC yaitu dengan melakukan Inisiasi Menyusui Dini dan kontak kulit bayi dengan kulit ibu. Secara keseluruhan bayi Ny.M.G.L sudah mendapat asuhan segera pada bayi baru lahir.

\section{d. Asuhan Kebidanan Nifas}

1) Pengkajian ke 1 (6 jam post partum)

Dari hasil anamnesa didapat data ibu mengatakan masih merasa mules pada perutnya hal ini wajar karena ibu menngalami involusi uterus. involusi uterus yaitu kembalinya uterus ke bentuk semula(Saleha,2009). Dari hasil pemeriksaan keadaan umum baik, kesadaran composmentis, TD: 100/70 mmHg, 
nadi : $82 \mathrm{x} /$ menit, pernapasan : $21 \mathrm{x} /$ menit, suhu : $36,5^{\circ} \mathrm{C}$, kandung kemih kosong, TFU 2 jari dibawah pusat, kontraksi keras. Setelah plasenta lahir TFU 2 jari dibawah pusat, kontraksi keras, sehingga dapat disimpulkan bahwa involusi uteri ibu sesuai dengan batas normal,hal ini ditunjang dengan hasil inspeksi perdarahan ibu selama post partum $\pm 200 \mathrm{cc}$ yang berarti tidak terjadi perdarahan yang abnormal pada masa post partum dikarenakan perdarahan primer maupun sekunder. Pengeluaran lochea rubra berwarna merah segar hal ini sesuai dengan teori bahwa lochea pada hari pertama sampai hari ketiga masa nifas adalah lochea rubra dengan warna merah segar(Saleha 2009).

Dari hasil anamnesa dan pemeriksaan didapatkan analisa diagnosa kebidanan Ny.M.G.L usia 26 tahun P2A0 6 jam post partum normal. Asuhan yang diberikan pada ibu bersalin post partum normal yaitu mengajarkan ibu melakukan masase, menganjurkan ibu untuk memberi ASI eksklusif pada bayi. Bayi dilakukan rawat gabung, hal ini seusai dengan dimana pada 6-8 jam seharusnya dilakukan rooming in atau rawat gabung. Menganjurkan ibu makan makanan yang bergizi seimbang agar segera pulih yaitu kebutuhan nutrisi harus seimbang mulai dari karbohidrat, lemak, protein, vitamin dan mineral.

\section{2) Pengkajian ke-2 ( Hari ke 7 post partum ).}

Pada tahap ini pengumpulan data di lakukan lewat telepon (Telemedicine) antara pasien, bidan puskesmas pembantu Golodukal dan penulis. Pengkajian selanjutnya dilakukan pada tanggal 22 Mei 2020 ibu mengatakan perutnya masih terasa mules, perdarahan sedikit berwarna merah kecoklatan dan mengganti pembalut 2 kali sehari. ASI keluar lancar dan bayi menyusu dengan kuat. Hasil pemeriksaan petugas puskesmas pembantu Golodukal tanda-tanda vital TD $110 / 70 \mathrm{mmHg}$, nadi $80 \mathrm{x} /$ menit, pernapasan $20 \mathrm{x} /$ menit, suhu $36,8^{\circ} \mathrm{C}$, keadaan umum baik, kesadaran composmentis, ASI lancar, TFU 2 jari diatas sympisis, lokhea sanguinolenta warna merah kecoklatan. Dari hasil pemeriksaan TFU sudah sesuai dengan teori yang menyatakan bahwa tinggi fundus uteri 1 minggu post partum adalah pertengahan antara pusat dan simpisis. Untuk perdarahan berwarna merah kecoklatan ini sesuai dengan teori bahwa lokhea sanguinolenta keluar pada hari ke-3 sampai hari ke-7 berwarna merah kecoklatan. Berdasarkan dari hasil anamnesa ibu mengatakan ASI-nya lancar dan hasil pemeriksaan ASI ibu keluar dengan lancar berwarna putih, dan tidak ada bendungan ASI.

Berdasarkan data di atas dapat di simpulkan bahwa jenis air susu ibu yang keluar adalah ASI matur hal ini sesuai dengan teori yang menyatakan pada hari ke 7-11 dan seterusnya jenis ASI yang keluar adalah matur berwarna putih(Marmi K 2015). Banyaknya ASI pada Ny.M.G.L ini ditunjang dengan terpenuhinya nutrisi sehingga membantu produksi ASI semakin banyak. Pada kunjungan ini tidak menunjukkan adanya tanda bahaya masa nifas. Sesuai dengan teori tanda bahaya masa nifas antara lain : perdarahan lewat jalan lahir, keluar cairan berbau dari jalan lahir, demam, bengkak di muka, tangan atau kaki, disertai sakit kepala dan atau kejang, nyeri atau panas di daerah tungkai, payudara bengkak, berwarna kemerahan dan sakit, puting lecet dan ibu mengalami depresi (antara lain menangis tanpa sebab dan tidak peduli pada bayinya). Asuhan yang diberikan kepada Ny.M.G.L menganjurkan ibu untuk sering memberikan ASI kepada bayinya sesering mungkin, makan-makanan yang bergizi seimbang, menjaga bayi agar tetap hangat. 
3) Pengkajian ke 3- KF III ( hari ke 30 post partum normal).

Pada tahap ini juga pengumpulan data hanya lewat telepon (Telemedicine) antara pasien, petugas puskesmas pembantu Golodukal dan penulis dan dilakukan pada tanggal 10 Juni 2020 pukul 10.00 wita. Ibu mengatakan tidak ada keluhan, ASInya lancar dan bayi menyusu dengan kuat. Hasil pemeriksaan petugas pustu keadaan umum baik, tanda - tanda vital dalam batas normal. Uterus sudah tidak teraba, lokea berwarna putih yaitu lokea alba, luka jahitan sudah kering dan tidak ada tanda infeksi. Asuhan yang diberikan sesuai pelayanan KF 3 yaitu memberikan konseling macam-macam metode kontrasepsi dan ibu bersedia untuk ikut KB pada tanggal 19 Juni 2020 dan ibu memilih metode kontrasepsi KB suntikan 3 bulanan.

e. Asuhan Kebidanan Neonatus

1) Pengkajian I - KN I (6 jam neonatus normal)

Pada kunjungan pertama dilakukan 3 jam setelah bayi lahir dan didapatkan bayi lahir cukup bulan dengan usia kehamilan 39 minggu 3 hari berdasarkan data tersebut bayi Ny.M.G.L tergolong neonatus cukup bulan yaitu klasifiksai menurut masa gestasi neonatus cukup bulan (37-42 minggu). Dari hasil anamnesa bayi Ny.M.G.L pada saat 6 jam pertama sudah BAK dan sudah BAB. Hal ini sesuai dengan teori menyatakan bahwa bayi baru harus sudah buang air besar dan buang air kecil sebelum 24 jam pertama. Berdasarkan hasil inspeksi didapatkan seluruh tubuh bayi kemerahan, dan didapatkan hasil tanda vital suhu $36,8^{\circ} \mathrm{C}$, hal ini normal menurut teori yang menyatakan bahwa batas normal suhu tubuh bayi antara 36,5-37,5 C. Berdasarkan data tersebut dapat disimpulkan neonatus tidak mengalami hipotermi dan hipertermi. Sedangkan hasil pemeriksaan tali pusat, didapatkan tali pusat bersih, masih basah dan tidak terdapat tanda-tanda perdarahan. Sehingga dapat disimpulkan bahwa tidak terdapat tanda-tanda infeksi atau perdarahan tali pusat, seperti teori yang menyatakan bahwa tandatanda infeksi pada tali pusat antara lain : tali pusat bernanah, merah, bengkak, dan nampak pembesaran perut(Muslihatun 2009).

2) Pengkajian II - KN II (hari 7 neonatus normal)

Pengkajian ke 2 dilakukan pada 7 hari setelah bayi lahir. Dari hasil anamnesa tali pusat belum lepas, hal ini sesuai dari teori yang menyatakan bahwa tali pusat akan lepas pada hari ke 7 hingga hari ke 10. Selain itu, ibu juga menyatakan jika bayi BAK 7x/hari dan BAB 3x/hari. Hal ini normal sesuai teori yang menyatakan bahwa miksi bayi minimal 6 kali sehari, defeksi 4-6 kali sehari. Asuhan yang diberikan pada kunjungan ini adalah menganjurkan ibu memberi ASI kapan saja (on demand) hal ini sesuai dengan teori yaitu bayi harus disusui kapan saja ia mau, siang atau malam (on demand).

3) Pengkajian III - KN III ( hari ke 11)

Hasil pemeriksaan KU baik, TTV normal,refleks-refleks normal. Memberikan asuhan kebidanan KIE tentang imunisasi pada bayi.Hal ini sesuai dengan teori (Sudarti,2010) yang menyatakan bahwa imunisasi merupakan usaha memberikan kekebalan pada tubuh bayi.Proses neonatus Ny.M.G.L secara keseluruhan berjalan normal tanpa adanya masalah. .Ny.M.G.L mengikuti anjuran dan pendidikan kesehatan yang diberikan bidan untuk perawatan bayinya sehingga asuhan yang diberikan bidan berjalan dengan baik.

f. Asuhan Kebidanan Keluarga Berencana

Pelaksanaan asuhan keluarga berencana pada Ny. M.G.L telah dimulai pada kunjungan ke tiga masa nifas, yaitu konseling alat kontrasepsi pada masa nifas, metode kontrasepsi postpartum, yaitu MAL, kontrasepsi progestin, AKDR, AKBK, kondom, KB alamiah, kontrasepsi mantap. Ditinjau dari usia Ny.M.G.L saat ini, yaitu 26 tahun alat kontrasepsi yang dianjurkan dapat digunakan MAL, pil, 
KB suntik 3 bulan, implan, AKDR. Berdasarkan konseling Ny.M.G.L memilih alat kontrasepsi suntik 3 bulan. Alat kontrasepsi suntik 3 bulan mengandung progestin, yaitu depo medroksiprogesteron asetat (DMPA) dengan cara kerja mencegah ovulasi sehingga menurunkan penetrasi sperma. Pemberian dilakukan setiap 3 bulan dengan cara disuntikkan IM pada daerah bokong. Tanggal 19 Juni 2020 dilakukan pemberian alat kontrasepsi suntik 3 bulan secara IM pada bokong. Berdasarkan praktik dilapangan menunjukkan tidak ada kesenjangan teori dan praktik.(biran 2013).
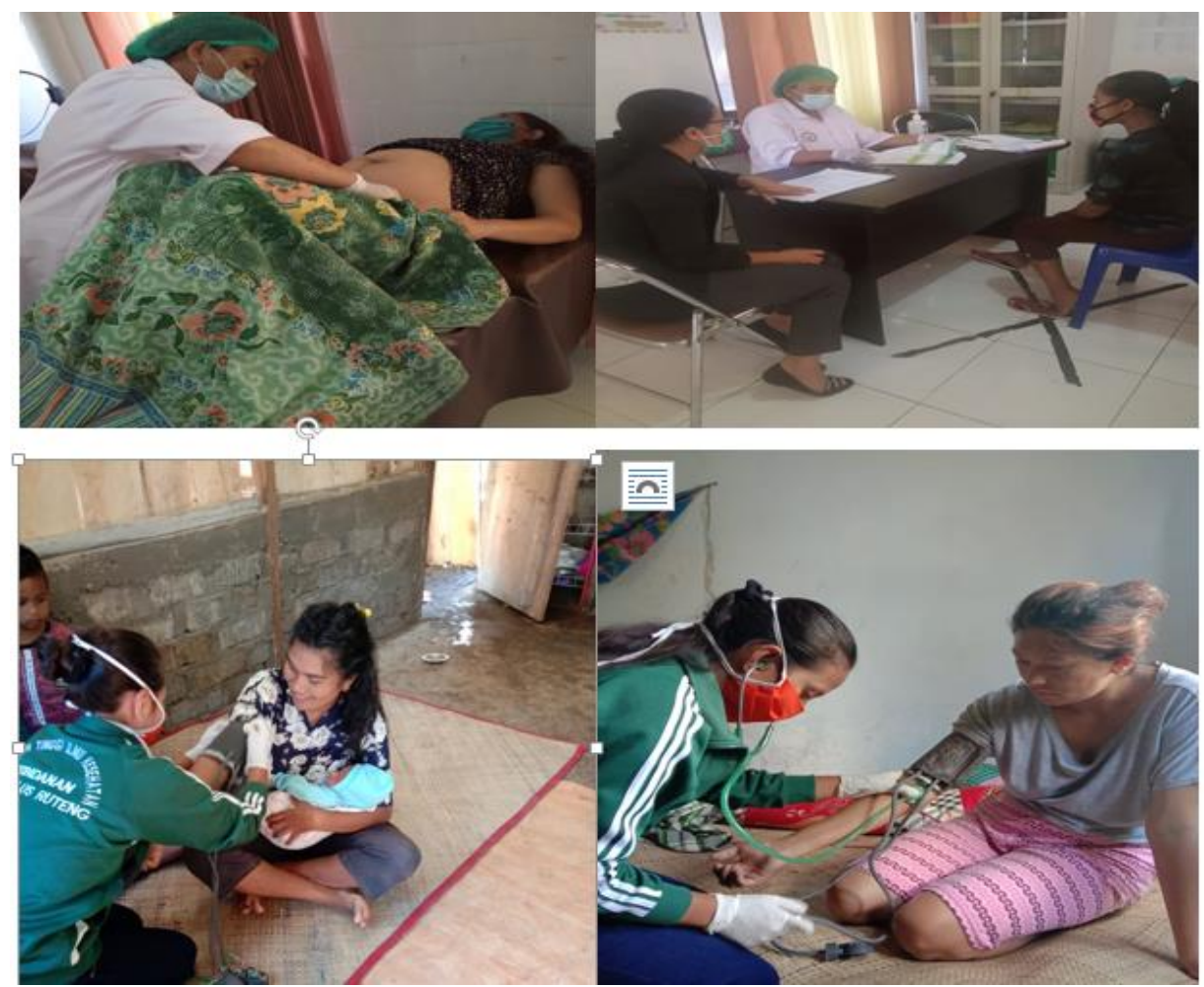

Gambar 2.2 Pelaksanaan Kegiatan PKM

\section{KESIMPULAN}

Setelah penulis melaksanakan pendampingan selama hamil, bersalin, bayi baru lahir, nifas, neonatus sampai KB pada Ny.M.G.L yang dimulai pada usia kehamilan 30 minggu 3 hari sampai KB dapat diambil kesimpulan sebagai berikut:

a. Pada saat hamil Ny.M.G.L melakukan ANC rutin di Pustu Golodukal dan Tempat praktik dokter spesialis kandungan. Pada masa kehamilan Ny.M.G.L dari trimester I sampai trimester III berlangsung normal.

b. Pada proses persalinan Ny.M.G.L termasuk persalinan normal walaupun pada kala III ada penyulit yaitu retensio placenta tetapi bisa di atasi dengan manual placenta dan ibu dalam keadaan sehat. Suami juga berperan dalam mendampingi proses persalinan.

C. Asuhan kebidanan pada Bayi Ny.M.G.L bayi lahir jam 03.00 wita, jenis kelamin laki-laki, hasil penilaian awal bayi menangis kuat, gerak kuat, warna kulit kemerahan, BB 3000 gram, PB $50 \mathrm{~cm}$.

d. Pada masa nifas pengkajian 1,2 dan 3 ibu normal tidak ada masalah.

e. Asuhan neonatus pada bayi Ny.M.G.L, tidak ada kelainan serta bayi dapat melalui masa neonatusnya dengan normal. 
f. Asuhan keluarga berencana dilakukan dengan konseling alat kontrasepsi, pemilihan alat kontrasepsi yang sesuai, informed consent, penapisan klien dan pelayanan alat kontrasepsi pilihan ibu Ny.M.G.L yaitu memilih alat kontrasepsi suntik 3 bulan dan tanggal 19 Juni 2020 ibu sudah menjadi akseptor KB baru suntika 3 bulanan.

\section{UCAPAN TERIMA KASIH}

a. Terima kasih kepada bidan Rofina N.Fariyani Amd.Keb sebagai bidan coordinator di Puskesmas Pembantu Golodukal yang telah memberikan kesempatan dan masukkan sehingga kegiatan Pengabdian Kepada Msayarakat ini dapat berjalan dengan Lancar

b. Terima Kasih Kepada Ny. $R$ yang bersedia untuk dilakukan asuhan kebidanan berkelanjutan mulai dari kehamilan, persalinan, Bayi baru lahir, nifas , neonates dan Keluarga Berencana

\section{DAFTAR PUSTAKA}

Biran, Afandi. (2013). Buku Panduan Praktis Pelayanan Kontrasepsi. 3rd ed. Jakarta: PT Bina Pustaka SARWONO PRAWIROHARDJO.

Dewi, V. N. L. (2010). Asuhan Neonatuys Bayi Dan Anak Balita. Jakarta: Salemba Medica.

Dinas Kesehatan Kabupaten Manggarai. (2017). Laporan Kinerja Tahun 2017.

Dinkes NTT. (2018). “Ntt Bangkit Ntt Sejahtera." Profil Kesehatan Provinsi Nusa Tenggara Timur.

Kemenkes RI. (2019). Profil Kesehatan Indonesia 2018 [Indonesia Health Profile 2018]. http://www.depkes.go.id/resources/download/pusdatin/profilkesehatan-indonesia/Data-dan-Informasi_Profil-Kesehatan-Indonesia2018.pdf.

KEMENKES RI. (2017). Profil Kesehatan Indonesia Tahun 2016. Jakarta. https://www.kemkes.go.id/resources/download/pusdatin/profilkesehatan-indonesia/Profil-Kesehatan-Indonesia-2016.pdf.

Marmi K, R. (2015). Asuhan Neonatus, Bayi, Balita, Dan Anak Prasekolah. Yogyakarta: Pustaka Belajar.

Muslihatun, W.N. (2009). Dokumentasi Kebidanan. Yogyakarta: Citramaya.

Padeng, Eufrasia Prinata et al. 2021. “PROMOSI KESEHATAN IBU HAMIL MELALUI PENDEKATAN SENAM HAMIL DI PUSTU GOLODUKAL WILAYAH KERJA PUSKESMAS LAO RUTENG KABUPATEN MANGGARAI NUSA TENGGARA TIMUR." 4: 6.

Rahayu, Fitri. (2018). “Asuhan Kebidanan Pada Ny 'E' Masa Hamil TM III, Bersalin, Nifas, Neonatus, Keluarga Berencana Di PMB Purwantini, S.Tr.Keb Desa Bacem Kecamatan Kebonsari Kabupaten Madiun." Universitas Muhamhmadiyah Gersik 01: 1-7.

Saleha, S. (2009). No Title. Jakarta: Salemba Medica.

Sarwono Prawirhadjo. (2010). Ilmu Kebidanan. Jakarta: Bina Pustaka Sarwono Prawirohardjo.

Varney, H. (2008). Buku Ajar Asuhan Kebidanan. Jakarta: EGC.

Wahyuni, S., Wahyuningsih, E. (2015). "Pengaruh Massage Effleurage Terhadap Tingkat Nyeri Persalinan Kala I Fase Aktif Pada Ibu Bersalin Di RSU PKU Muhammadiyah Delanggu Klaten 2015." Jurnal Involusi Kebeidanan 5(10): 43-53. 